\title{
Fluorine F 18 FP-R01-MG-F2
}

National Cancer Institute

\section{Source}

National Cancer Institute. Fluorine F18 FP-R01-MG-F2. NCI Thesaurus. Code C124230.

A radiotracer composed of the integrin alphaVbeta6 (aVb6) lig and and cystine knot peptide R01 variant R01-MG-F2 radiolabeled with [18F]-fluoropropionate (F 18 FP), with potential integrin aVb6 imaging activity using positron emission tomography (PET). Upon administration, the R01-MG-F2 moiety of fluorine F 18 FP-R01-MG-F2 selectively binds to integrin aVb6-positive cancer cells. During PET, aVb6-expressing tumor cells can be visualized. Integrin aVb6, a cell adhesion and signaling receptor, is upregulated in certain cancer cell types and has been associated with increased proliferation of tumor cells. The cystine knot peptide shows high stability and allows for rapid and high uptake into aVb6expressing tumor cells. 